\title{
Dementia and Caregiver Burden:
}

\section{A Three Year Longitudinal Study}

Michael H. Connors, ${ }^{1,2}$ Katrin Seeher, ${ }^{1,2}$ Armando Teixeira-Pinto, ${ }^{3}$

Michael Woodward, ${ }^{4}$ David Ames, ${ }^{5,6}$ and Henry Brodaty ${ }^{1,2}$

${ }^{1}$ Dementia Centre for Research Collaboration, School of Psychiatry, UNSW Australia, Sydney, Australia

${ }^{2}$ Centre for Healthy Brain Ageing, School of Psychiatry, UNSW Australia, Sydney, Australia ${ }^{3}$ School of Public Health, University of Sydney, Sydney, Australia

${ }^{4}$ Austin Hospital, Heidelberg, Australia

${ }^{5}$ University of Melbourne Academic Unit for Psychiatry of Old Age, Melbourne Australia ${ }^{6}$ National Ageing Research Institute, Melbourne, Australia

Corresponding author:

Henry Brodaty

Dementia Centre for Research Collaboration

Level 3, AGSM Bldg (G27)

University of New South Wales

This is the author manuscript accepted for publication and has undergone full peer review but has not been through the copyediting, typesetting, pagination and proofreading process, which may lead to differences between this version and the Version of Record. Please cite this article as doi: $10.1002 /$ gps.5244

This article is protected by copyright. All rights reserved. 
NSW 2052, Australia

Phone: (+61 2) 93852585

Fax: $\quad(+612) 93852200$

Email: h.brodaty@unsw.edu.au

This article is protected by copyright. All rights reserved. 


\begin{abstract}
Objectives. Dementia, with its progressive cognitive and functional decline and associated neuropsychiatric symptoms, places a large burden on caregivers. While frequently studied, longitudinal findings about the overall trajectory of burden are mixed. The study sought to characterise caregiver burden over a three-year period and identify predictors of this burden.

Methods. Seven-hundred-and-eighty-one patients with dementia were recruited from nine memory clinics around Australia. Measures of caregiver burden, cognition, function, and neuropsychiatric symptoms were completed with patients and their caregivers at regular intervals over a three-year period. Patients' level of services and medication use were also recorded.
\end{abstract}

Results. Of the 720 patients with measures of caregiver burden at baseline, $47.4 \%$ of caregivers had clinically significant levels of burden. This proportion increased over time, with $56.8 \%$ affected at three years. Overall levels of burden increased for caregivers of patients without services, though did not change for caregivers of patients receiving services or residential care after controlling for other variables. Patient characteristics - including greater neuropsychiatric symptoms, lower functional ability, fewer medications, lack of driving ability - and female sex of caregivers were associated with greater burden.

Conclusions. High levels of caregiver burden are present in a large proportion of caregivers of people with dementia and this increases over time for those without services. Clinical characteristics of patients (including neuropsychiatric symptoms, function, overall health, driving status), level of services, and caregiver sex appear to be the best predictors of this burden. These characteristics may help identify caregivers at greater risk of burden to target for intervention.

This article is protected by copyright. All rights reserved. 
Keywords: Alzheimer's disease, carer burden, caregiver burden, dementia, longitudinal, neuropsychiatric symptoms, vascular dementia 


\section{Key Points}

- Dementia, with its associated cognitive and functional impairments and frequent neuropsychiatric symptoms, can place a large burden on caregivers.

- In a three-year longitudinal study of nine memory clinics, we found that around half of caregivers had clinically significant levels of burden with this increasing over time, particularly for those at home without services.

- Patient characteristics - including neuropsychiatric symptoms, severity of functional impairment, inability to drive, and fewer medications - and level of services and caregiver sex predicted overall burden.

This article is protected by copyright. All rights reserved. 


\section{Introduction}

Dementia, with its progressive cognitive and functional decline and associated neuropsychiatric symptoms, places a considerable burden on caregivers. ${ }^{1,2}$ Caregivers face both instrumental challenges - attending to the needs and symptoms of patients - and emotional challenges - coping with a loved one's ongoing deterioration, as well as their own loss of independence, increased social isolation, and financial pressures. As a result, caregivers typically exhibit higher levels of stress and depression, poorer physical health, and reduced levels of employment than the general population. ${ }^{3-5}$ Given the prevalence of dementia $-5 \%$ of people over the age of $60^{6}$ - this represents a significant issue at a population level. Caregivers, however, can vary considerably in their level of burden. As a result, an important goal is to identify caregivers at particular risk of high levels of burden to target for clinical intervention.

Previous cross-sectional research has identified several variables that predict burden. One set of variables is patients' clinical characteristics. These represent primary stressors for caregivers and include patients' neuropsychiatric symptoms and cognitive and functional impairments. Of these, neuropsychiatric symptoms have been noted to be particularly burdensome. ${ }^{7-10}$ Patients' cognitive and functional impairments have also been associated with greater burden, though not consistently. ${ }^{8,9}$ In a related manner, driving cessation, which occurs as a result of these impairments, has been indirectly associated with greater burden, with caregivers of patients who stop driving having higher burden at an earlier assessment than those who did not. ${ }^{11} \mathrm{~A}$ second set of variables that predict burden is caregiver characteristics and background contextual variables. Spousal relationships, ${ }^{12}$ female sex of caregiver, ${ }^{3}$ living at home, ${ }^{13}$ and cohabiting with the patient ${ }^{14}$ have been associated with greater caregiver burden.

This article is protected by copyright. All rights reserved. 
Longitudinal findings are more mixed as to the overall trajectory of burden. Some studies suggest that burden remains relatively stable over time; ${ }^{-15-17}$ others suggest burden increases; ${ }^{18-20}$ while others suggest that burden may even decrease. ${ }^{21}$ These findings are relevant given competing accounts of caregiving as either "wear-and-tear" - in which caregivers gradually become more overwhelmed with the ongoing toll of caregiving - or "adaptation" - in which caregivers become accustomed to the demands placed on them. ${ }^{22}$ Given these mixed findings, research has attempted to identify drivers of burden. Neuropsychiatric symptoms, in particular, have been identified as a key predictor of subsequent caregiver burden. ${ }^{16,23-25}$ By contrast, nursing home placement has been associated with a reduction in burden. ${ }^{26}$ Other variables, such as caregiver relationship, ${ }^{27}$ may also affect longitudinal trends. A limitation of some previous research, however, is that it has not controlled for the severity of patients' clinical symptoms when reporting the overall effect of time or considered the impact of patient attrition. Many studies have also been limited by a relatively short follow-up duration (typically only 1-2 years) and some have only considered two data points. Given the importance of neuropsychiatric symptoms to burden, a further issue is the limited longitudinal data on the relationship between individual neuropsychiatric symptoms and caregiver burden. ${ }^{28-30}$

To address these issues, we examined caregiver burden longitudinally in a sample of patients with dementia recruited from memory clinics. Patients with dementia and their caregivers were assessed regularly over three years. We used linear mixed models to analyse the data; these have the advantage of being able to handle missing data, including attrition, without the need for imputation. ${ }^{31}$ Based on previous research, we expected that a range of patient characteristics - such as higher levels of neuropsychiatric symptoms, greater cognitive and functional impairments, and poorer health - and background features - 
such as longer duration of symptoms, level of services, spousal relationships, and cohabitation - would predict caregiver burden. We also expected that burden would increase over time with the worsening of patients' impairments and symptoms.

\section{Methods}

\section{Design}

Participants were drawn from the Prospective Research in MEmory Clinics (PRIME) study, ${ }^{32,33}$ a three-year observational study of patients attending memory clinics. Of 964 patients recruited, 779 had dementia and 185 had mild cognitive impairment. All patients received specialist assessment or treatment at one of nine memory clinics around Australia. These memory clinics were in four of the eight states and territories of Australia and included both regional and capital centres (for more information about dementia services in Australia, see $\left.{ }^{34}\right)$. Patients, together with their caregiver as their informant, had annual follow-ups with a research nurse/psychologist or specialist clinician, with additional visits at 3 and 6 months. Ethics approvals were obtained from institutional ethics committees associated with individual referring centres (National Institute of Health clinical trials registry number: NCT00297271).

\section{Patients}

The current analyses focused on patients with dementia. All had received a diagnosis from a specialist clinician according to DSM-IV criteria. ${ }^{35}$ Patients were included in the PRIME study if they lived in the community, had less than 40 hours/week care, were fluent in 
English, had a caregiver consent to the study, and provided written informed consent either themselves or through a legal guardian/proxy. Patients with acute or life-threatening illness or requiring high level residential care at baseline were excluded.

\section{Instruments and Methods}

Assessments were completed by a specialist clinician or trained research nurse/psychologist. Demographic and diagnostic data were collected at baseline. All other measures were completed at each visit. Caregiver burden was assessed with the 22-item Zarit Burden Interview (ZBI); ${ }^{36}$ higher scores indicate greater burden (range 0-88), with a cutoff score of 24 indicating clinically significant burden. ${ }^{37}$ Dementia severity was assessed using the Clinical Dementia Rating (CDR) scale ${ }^{38}$ and scored using the sum of boxes method; ${ }^{39}$ higher scores indicate greater severity (range 0-18). Cognition was assessed using the Mini-Mental State Examination MMSE; ${ }^{40}$ higher scores indicate better cognition (range 0-30). Function was assessed using the Functional Autonomy Measurement System SMAF; ${ }^{41}$ higher scores indicate better function (range -87 to 0 ). Neuropsychiatric symptoms were assessed using the total score of the 12 -item Neuropsychiatric Inventory NPI; ${ }^{42}$ higher scores indicate greater frequency and severity of symptoms (range 0-144). Patients' level of services (no services, home services, low level residential care, high level residential care) was recorded at each visit. A list of medications that patients were taking at each visit was compiled.

\section{Statistical Analyses}

Continuous variables at baseline were reported by mean and standard deviation (SD); categorical variables were reported as frequencies (\%). Patients with complete ZBI data at baseline were compared to those who did not using logistic regression controlling for 
time from clinical diagnosis. Patients with complete ZBI data at the three-year follow-up were also compared to those who did not in terms of their characteristics at baseline in the same manner. Patients whose caregiver changed over the study were compared to the rest of the sample in the same way.

Longitudinal data across all time points were analysed using linear mixed models with normally distributed random intercepts and random effects for time. Time was measured in years from patients' dementia diagnosis. The outcome measure across time was caregiver burden (ZBI score) as a continuous measure. For patients, the following predictors were included in the model: at baseline - age, sex, type of dementia - and at each time point - cognition (MMSE), function (SMAF), dementia severity (CDR), neuropsychiatric symptoms (NPI total), driving status, level of services (no services, home services, low level residential care, high level residential care), and total number of medications (as a proxy for physical health). ${ }^{43}$ For caregivers, the following variables were included: sex, caregiver relationship (spouse versus other relationship), living arrangement (lives with patient versus lives separately), and employment status at baseline. An interaction between level of services and time was tested and retained in the model if $p<0.10$. Given the previously reported relationships between sex and driving status in older age, ${ }^{44-46}$ interactions between patient sex and driving and between caregiver sex and driving were also tested. Models were selected based on the Akaike information criterion.

To examine the contribution of individual neuropsychiatric symptoms on caregiver burden, an analysis was conducted in which individual NPI sub-scores (delusions, hallucinations, agitation/aggression, depression, anxiety, euphoria, apathy, disinhibition, irritability, aberrant motor behaviour, night-time behaviour, and appetite) were included as predictors while controlling for age, sex, function, number of medications, antipsychotic 
medication, and level of services. To reduce the impact of change in caregiver on the results, both analyses were repeated excluding patients who changed caregivers after the change in caregiver occurred. All analyses were completed with SPSS (version 25).

\section{Results}

\section{Baseline Characteristics}

Of the 779 patients with dementia, 720 (92.4\%) had the ZBI completed by a caregiver. Patients who had the ZBI completed were taking more medications $(O R=1.16$, 95\% Cl 1.05-1.28) than patients who did not, but did not differ in age, sex, or any other clinical and demographic variables. Patients who had ZBI data completed at the three-year follow-up were younger $(O R=0.95,95 \% \mathrm{Cl} 0.93-0.97)$; had higher cognition scores $(O R=$ 1.10, 95\% $\mathrm{Cl} 1.07-1.13)$, higher functioning scores $(\mathrm{OR}=1.06,95 \% \mathrm{Cl}$ 1.05-1.08), lower dementia severity scores $(O R=0.84,95 \% \mathrm{Cl} 0.80-0.88)$, lower neuropsychiatric symptom scores $(O R=0.98,95 \% \mathrm{Cl} 0.97-0.99)$ and lower caregiver burden scores $(O R=0.98,95 \%$ $\mathrm{Cl} 0.97-0.99)$. They were also more likely to be driving $(\mathrm{OR}=2.44,95 \% \mathrm{Cl} 1.78-3.34)$ and have a spouse as a caregiver $(O R=1.40,95 \% \mathrm{Cl} 1.02-1.93)$, but did not differ in sex, number of medications, or other characteristics at baseline. Caregivers changed for 19 patients during the study. These patients were more likely to have caregivers who were working $(O R=3.70,95 \% \mathrm{Cl} 1.12-12.28)$, but did not differ from other patients in the study in any other clinical or demographic variables in logistic regression analyses.

Demographic features of patients and their caregivers are summarised in Table 1. Of the 720 patients with completed ZBI data, 633 (87.9\%) did not receive services; 71 (9.9\%) accessed home services; and 16 (2.2\%) were living in low level residential care (patients requiring high level residential care at baseline were excluded).

---Insert Table 1 about here---

This article is protected by copyright. All rights reserved. 


\section{Caregiver Burden during the Study}

Numbers of patients across the study are shown in Figure 1. Reported caregiver burden increased over the study. Mean levels of caregiver burden were $24.0(S D=15.8)$ at baseline, $25.6(S D=17.0)$ at three months, $26.1(S D=17.1)$ at six months, $27.4(S D=18.9)$ at one year, $28.9(S D=19.0)$ at two years, and $30.7(S D=21.3)$ at three years. Clinically significant levels - indicated by scores of 24 or more - were present in $47.4 \%$ of the sample at baseline, $49.1 \%$ at three months, $49.8 \%$ at six months, $51.6 \%$ at one year, $52.5 \%$ at two years, and $56.8 \%$ at three years. At three years, $283(76.9 \%)$ of the patients remaining in the study had no services, 41 (11.1\%) had home services, 18 (4.9\%) had low level residential care, and $26(7.1 \%)$ had high level residential care.

---Insert Figure 1 about here---

Regression analysis from the linear mixed models showed an interaction between time and level of services (see Table 2). At time of diagnosis, caregivers of patients receiving home services had 7.9 points greater burden relative to caregivers of those at home without services, while caregivers of patients in low level residential care had 8.9 points less burden relative to caregivers of those at home without services. Over time, however, caregivers of patients living at home without services had significant increases in burden by an average 0.7 points on the $\mathrm{ZBI}$ annually while controlling for other variables. By contrast, caregivers of patients at home with services and those with low level and high level residential care showed no significant changes in burden over time. There was also substantial variability in longitudinal trends: The standard deviation of 2.5 for the random effect of time indicates that the change in caregiver burden for patients at home without services varied from -4.2 (percentile 2.5) to 5.6 (percentile 97.5) points on the ZBI each year. There were no 
significant interactions between driving status and either patient sex or caregiver sex, so these terms were removed from the model.

Patients' function, neuropsychiatric symptoms, driving status, number of medications, level of services, and caregiver sex predicted caregiver burden (see Table 2). For functional impairment, each point worsening in function on the SMAF scale was associated with a 0.2 point increase in caregiver ZBI score, as shown in Table 2. Likewise, each point increase in neuropsychiatric symptoms on the NPI scale was associated with a 0.3 point increase in caregiver ZBI score. Each additional medication was associated with 0.3 less burden and caregiver's female sex was associated with 5.3 points greater burden compared to males. Not driving in patients was associated with 2.5 points greater burden than driving. There were also trends for lower patient age, cohabiting with the patient, and non-spousal relationships (correcting for cohabitation) to be associated with greater burden. There was no association between caregiver burden and type of dementia, patient sex, dementia severity, cognition, or caregiver employment once other variables were controlled for.

\section{---Insert Table 2 about here---}

A further analysis examined different types of neuropsychiatric symptoms. This found that delusions, hallucinations, agitation, depression, anxiety, euphoria, apathy, irritability, aberrant motor behaviour, and appetite disturbances were all predictors of caregiver burden controlling for age, sex, function, antipsychotic medication use, number of medications, level of services, and time since diagnosis (see Table 3). The largest effects were seen for agitation and depression. Disinhibition and night-time behaviour did not predict burden once other variables were controlled for.

---Insert Table 3 about here---

This article is protected by copyright. All rights reserved. 
All results were unchanged when the 19 patients who switched caregivers were excluded from the analyses (results not shown).

\section{Discussion}

A large proportion of caregivers experienced clinically significant levels of caregiver burden in this study. Around half of caregivers exhibited clinically significant levels of burden, with the proportion affected increasing steadily over the three-year period. While these figures are consistent with previous research, the current study extends previous findings by demonstrating an interaction between time and level of services. In particular, the findings showed that caregiver burden increases over time for patients without services after controlling for patients' clinical symptoms and other characteristics, though may not change to the same degree for caregivers of patients with services at home and in residential care. In addition, the current study confirms that patients' characteristics - specifically neuropsychiatric symptoms, lower function, fewer medications, and inability to drive - and caregiver sex and level of services also predict burden.

The overall increase in burden over time for patients' at home without services is consistent with some ${ }^{18,19}$ though not all previous studies. ${ }^{15-17}$ The current study controlled for clinical and demographic variables and showed that the duration of patients' symptoms, independent of their severity, was associated with greater caregiver burden. This suggests that burden may reflect the cumulative toll on caregivers and not just symptoms at a particular time point. Previous authors have argued that persisting demands on caregivers over time are likely to be associated with greater levels of burden than similar demands of shorter duration. ${ }^{47}$ Others ${ }^{24}$ have also noted that attrition of participants with the most severe symptoms could mask such effects and create the illusion of adaptation, particularly in 
studies of shorter duration. In this regard, a strength of our approach was the use of linear mixed models, which deals with missing data in longitudinal analyses. ${ }^{31}$ Nevertheless, significant variability in changes in burden over time was evident, indicating the need for further research to identify drivers of longitudinal trends.

For patients with services at home or who were living in residential facilities, the study found no changes in caregiver burden over time after controlling for demographic and clinical variables. In addition, caregivers of patients in low level residential care experienced lower levels of burden at time of diagnosis compared to caregivers of patients living at home without services after controlling for other variables. This suggests that supported accommodation, by alleviating some instrumental demands of caregiving, can help reduce overall levels of burden. By contrast, caregivers of patients with home services experienced greater burden at time of diagnosis than caregivers of patients living at home without services. Greater neuropsychiatric symptoms, which are associated with caregiver burden, could hasten access to home support, as may greater caregiver burden directly. At the same time, home services may be insufficient to meet the needs of many caregivers for patients in the community or there may be a delay in obtaining nursing home placement when this is warranted, giving rise to the higher levels of burden. While the lack of change of burden over time for these caregivers with different levels of services could suggest a level of adaptation, these analyses were limited by the relatively small numbers of patients in these groups.

The finding that neuropsychiatric symptoms and functional decline are associated with greater caregiver burden is consistent with previous research..$^{8,9,28,48}$ These features represent primary stressors for caregivers and are, not surprisingly, related to the level of caregiver burden. ${ }^{49}$ In the case of neuropsychiatric symptoms, the current study confirmed 
that almost all neuropsychiatric symptoms assessed by the NPI - delusions, hallucinations, agitation/aggression, depression, anxiety, apathy, irritability, and aberrant motor behaviour were independent predictors of caregiver burden, with agitation and depression having the greatest effects. Previous cross-sectional research has reported mixed findings as to whether certain symptoms are more significant to burden than others, though have noted agitation and depression as amongst the most troublesome. ${ }^{28-30,50}$ In the case of functional decline, previous research has likewise found such impairments to be associated with burden, though less reliably than neuropsychiatric symptoms. In one previous review, one third of studies demonstrated an association between functional impairment and burden. ${ }^{9}$

Importantly, the current study also showed that patients' driving status is a significant predictor of caregiver burden, even after controlling for functional impairment and other variables. Driving cessation is another feature representing degree of dependence and is likely to be a primary stressor for caregivers. While the significant impact of driving cessation on patients' and caregivers' lives has been known for some time ${ }^{51}$ comparatively little research has quantified the psychological impact in terms of caregiver burden longitudinally. One previous study noted that the caregivers of patients who ceased driving had higher levels of caregiver burden at an earlier baseline assessment than those who did not. ${ }^{11}$ As this analysis focused on levels of burden prior to driving cessation, the direction of the relationship remained unclear and could be attributable to associated clinical impairments. The current study, which assessed burden longitudinally and controlled for other variables, provides evidence for a more direct, causal relationship.

Other characteristics were associated with increased burden. Number of medications was negatively associated with burden and there was likewise a trend for patient age to be 
negatively associated with burden as well. Similar findings for patient age have been reported before. ${ }^{52,53}$ Explanations include the possibility that caregivers of younger patients encounter a greater discrepancy between their life expectations and present experience; have greater competing role demands; and face the prospect that their burden will endure for longer than those of older patients. Similar explanations could potentially be advanced for healthier patients; a greater number of medications could also reflect greater contact with the healthcare system, which could also potentially be associated with less burden. Finally, consistent with previous research, ${ }^{3,8}$ female sex of the caregiver, controlling for cohabitation, was associated with greater burden. Previous authors have noted that women typically provide more personal care, are more likely to complete household tasks at lower levels of patient impairment, and are more likely to report burden than men. ${ }^{54-56}$ Other demographic variables and patients' cognition and dementia severity were not related to caregiver burden once other variables were controlled for.

Limitations of the study include the convenience sampling of patients and the limited data collected on caregivers, which did not contain certain demographic information (e.g., age, education); caregiving arrangements (e.g., number of hours worked, sharing of caregiving responsibilities, informal supports); caregivers' driving status; or measures of mood, coping strategies and comorbidities. Previous research has found that, while more time caregiving is associated with greater burden, ${ }^{7}$ levels of burden may be moderated by caregiver's coping strategies and appraisals of patient's symptoms. ${ }^{57}$ The current study was also limited by the fact that it did not specifically assess caregiving "uplifts" - such as feeling useful or increased closeness with the patient - that are not indexed in the ZBI. ${ }^{7}$ Previous research has shown that such uplifts are associated with lower levels of burden. ${ }^{7}$ Finally, as 
for all cohort studies, it is possible that attrition, if non-random, could affect the study's findings.

\section{Conclusion}

Despite these limitations, the study further highlights the high levels of caregiver burden associated with dementia and the characteristics of patients and caregivers that predict this. In particular, the study confirms that patients' neuropsychiatric symptoms especially agitation and mood disturbances - remain a large determinant of burden over time. In addition, the study underscores the significant contribution of other risk factors, such as functional impairment, level of services, time since diagnosis, patients' health and driving status, and caregiver sex, many of which have received less attention. Such characteristics may be useful to identify caregivers with high levels of burden who might benefit from more timely intervention. 


\section{Data Availability}

Data are available on request from the authors.

\section{Acknowledgements}

The Dementia Centre for Research Collaboration - Assessment and Better Care is funded by the National Health and Medical Research Council. Data collection was funded in part by Janssen-Cilag Pty Limited. Janssen-Cilag had no input into the design, execution, analysis, interpretation, or writing of this study. We are grateful to the staff across nine testing sites and the patients and their families who supported this study.

\section{Conflict of Interest Declaration}

In the last three years, David Ames has received grants/funds for clinical trials from Eli Lilly and royalties for edited books from Cambridge University Press and Taylor \& Francis. Michael Woodward has worked on drug trials funded by pharmaceutical companies including AbbiVie, Astra Zeneca, AZ therapies, Biogen, Buck, Eisai, Janssen, Lilly, Lundbeck, Merck/MSD, Novartis, Pfizer, Roche, Servier, Takeda, Tau Rx, vTv Therapeutics and Zinfandel. He has also received honoraria for consultancy or presentations at meetings organized by CogRx, Lundbeck, Merck Sharp \& Dohme, Novartis, and Nutricia. Henry Brodaty is an advisory board member for Nutricia Australia. Michael Connors, Katrin Seeher, and Armando Teixeira-Pinto have no conflicts of interest to declare.

This article is protected by copyright. All rights reserved. 


\section{References}

1. Seeher K, Brodaty H. Family carers of people with dementia. In: Ames D, O'Brien JT, Burns A, eds. Dementia. 5th ed: CRC Press; 2017:142-160.

2. Brodaty H. Caregivers and behavioral disturbances: Effects and interventions. Int Psychogeriatr. 1996;8:455-458.

3. Pinquart M, Sörensen S. Differences between caregivers and noncaregivers in psychological health and physical health: A meta-analysis. Psychology and Aging. 2003;18:250-267.

4. Alzheimer's Association. 2016 Alzheimer's disease facts and figures. Alzheimer's \& Dementia. 2016;12:459-509.

5. Vitaliano PP, Zhang J, Scanlan JM. Is caregiving hazardous to one's physical health? A meta-analysis. Psychological Bulletin. 2003;129:946-972.

6. Prince M, Bryce R, Albanese E, Wimo A, Ribeiro W, Ferri CP. The global prevalence of dementia: A systematic review and meta-analysis. Alzheimer's \& Dementia. 2013;9:63-75.e62.

7. Pinquart M, Sörensen S. Associations of stressors and uplifts of caregiving with caregiver burden and depressive mood: A meta-analysis. Journal of Gerontology: Psychological Sciences. 2003;58:P112-P128.

8. Schoenmakers B, Buntinx F, Delepeleire J. Factors determining the impact of caregiving on caregivers of elderly patients with dementia. A systematic literature review. Maturitas. 2010;66:191-200.

9. van der Lee J, Bakker TJEM, Duivenvoorden HJ, Dröes R-M. Multivariate models of subjective caregiver burden in dementia: A systematic review. Ageing Res Rev. 2014;15:76-93.

This article is protected by copyright. All rights reserved. 
10. Isik AT, Soysal P, Solmi M, Veronese N. Bidirectional relationship between caregiver burden and neuropsychiatric symptoms in patients with Alzheimer's disease: A narrative review. Int J Geriatr Psychiatry. 2018;0.

11. Seiler S, Schmidt H, Lechner A, et al. Driving cessation and dementia: Results of the Prospective Registry on Dementia in Austria (PRODEM). PLOS ONE. 2012;7:e52710.

12. Pinquart M, Sörensen S. Spouses, adult children, and children-in-law as caregivers of older adults: A meta-analytic comparison. Psychology and Aging. 2011;26:1-14.

13. Brodaty H, Hadzi-Pavlovic D. Psychosocial effects on carers of living with persons with dementia. Aust N Z J Psychiatry. 1990;24:351-361.

14. Schulz R, O'Brien AT, Bookwala J, Fleissner K. Psychiatric and physical morbidity effects of dementia caregiving: Prevalence, correlates, and causes. The Gerontologist. 1995;35:771-791.

15. Berger G, Bernhardt T, Weimer E, Peters J, Kratzsch T, Frolich L. Longitudinal study on the relationship between symptomatology of dementia and levels of subjective burden and depression among family caregivers in memory clinic patients. Journal of Geriatric Psychiatry and Neurology. 2005;18:119-128.

16. Danhauer SC, McCann JJ, Gilley DW, Beckett LA, Bienias JL, Evans DA. Do behavioral disturbances in persons with Alzheimer's disease predict caregiver depression over time? Psychology and Aging. 2004;19:198-202.

17. Walker AJ, Acock AC, Bowman SR, Li F. Amount of care given and caregiving satisfaction: A latent growth curve analysis. The Journals of Gerontology: Series B Psychological Sciences and Social Sciences. 1996;51B:P130-P142.

This article is protected by copyright. All rights reserved. 
18. Conde-Sala JL, Turró-Garriga O, Calvó-Perxas L, Vilalta-Franch J, Lopez-Pousa S, Garre-Olmo J. Three-year trajectories of caregiver burden in Alzheimer's disease. Journal of Alzheimer's Disease. 2014;42:623-633.

19. Perales J, Turró-Garriga O, Gascón-Bayarri J, Reñé-Ramírez R, Conde-Sala JL. The longitudinal association between a discrepancy measure of anosognosia in patients with dementia, caregiver burden and depression. Journal of Alzheimer's Disease. 2016;53:1133-1143.

20. Park MH, Smith SC, Hendriks AAJ, Black N. Caregiver burden and quality of life 2 years after attendance at a memory clinic. Int J Geriatr Psychiatry. 2019.

21. Millenaar JK, de Vugt ME, Bakker C, et al. The impact of young onset dementia on informal caregivers compared with late onset dementia: Results from the NeedYD study. The American Journal of Geriatric Psychiatry. 2016;24:467-474.

22. Roth DL, Haley WE, Owen JE, Clay OJ, Goode KT. Latent growth models of the longitudinal effects of dementia caregiving: A comparison of African American and White family caregivers. Psychology and Aging. 2001;16:427-436.

23. Gaugler JE, Davey A, Pearlin LI, Zarit SH. Modeling caregiver adaptation over time: The longitudinal impact of behavior problems. Psychology and Aging. 2000;15:437450.

24. Gaugler JE, Kane RL, Kane RA, Newcomer R. The longitudinal effects of early behavior problems in the dementia caregiving career. Psychology and Aging. 2005;20:100-116.

25. van der Lee J, Bakker TJEM, Duivenvoorden HJ, Dröes R-M. Do determinants of burden and emotional distress in dementia caregivers change over time? Aging \& Mental Health. 2017;21:232-240.

This article is protected by copyright. All rights reserved. 
26. Gaugler JE, Mittelman MS, Hepburn K, Newcomer R. Clinically significant changes in burden and depression among dementia caregivers following nursing home admission. BMC Med. 2010;8:85-85.

27. Chappell NL, Dujela C, Smith A. Spouse and adult child differences in caregiving burden. Revue canadienne du vieillissement. 2014;33:462-472.

28. Feast A, Moniz-Cook E, Stoner C, Charlesworth G, Orrell M. A systematic review of the relationship between behavioral and psychological symptoms (BPSD) and caregiver well-being. Int Psychogeriatr. 2016;28:1761-1774.

29. Terum TM, Andersen JR, Rongve A, Aarsland D, Svendsboe EJ, Testad I. The relationship of specific items on the Neuropsychiatric Inventory to caregiver burden in dementia: A systematic review. Int J Geriatr Psychiatry. 2017;32:703-717.

30. Ornstein K, Gaugler JE. The problem with "problem behaviors": a systematic review of the association between individual patient behavioral and psychological symptoms and caregiver depression and burden within the dementia patient-caregiver dyad. Int Psychogeriatr. 2012;24:1536-1552.

31. Twisk J, de Boer M, de Vente W, Heymans M. Multiple imputation of missing values was not necessary before performing a longitudinal mixed-model analysis. Journal of Clinical Epidemiology. 2013;66:1022-1028.

32. Brodaty H, Woodward M, Boundy K, Ames D, Balshaw R. Patients in Australian memory clinics: Baseline characteristics and predictors of decline at six months. Int Psychogeriatr. 2011;23:1086-1096.

33. Brodaty H, Connors MH, Xu J, Woodward M, Ames D. The course of neuropsychiatric symptoms in dementia: A 3-year longitudinal study. J Am Med Dir Assoc. 2015;16:380-387.

This article is protected by copyright. All rights reserved. 
34. Brodaty H, Cumming A. Dementia services in Australia. Int J Geriatr Psychiatry. 2010;25:887-995.

35. American Psychiatric Association. Diagnostic and statistical manual of mental disorders, Fourth edition, Text Revision (DSM-IV-TR). Washington, DC: American Psychiatric Association; 2000.

36. Bédard M, Molloy DW, Squire L, Dubois S, Lever JA, O'Donnell M. The Zarit Burden Interview: A new short version and screening version. Gerontologist. 2001;41:652657.

37. Schreiner AS, Morimoto T, Arai Y, Zarit S. Assessing family caregiver's mental health using a statistically derived cut-off score for the Zarit Burden Interview. Aging \& Mental Health. 2006;10:107-111.

38. Morris JC. The Clinical Dementia Rating (CDR): Current version and scoring rules. Neurology. 1993;43:2412-2414.

39. O'Bryant SE, Waring SC, Cullum M, et al. Staging dementia using clinical dementia rating scale sum of boxes scores: A Texas Alzheimer's research consortium study. Arch Neurol. 2008;65:1091-1095.

40. Folstein MF, Folstein SE, McHugh PR. "Mini-mental state": A practical method for grading the cognitive state of patients for the clinician. J Psychiatr Res. 1975;12:189198.

41. Hébert R, Carrier R, Bilodeau A. The Functional Autonomy Measurement System (SMAF): Description and validation of an instrument for the measurement of handicaps. Age Ageing. 1988;17:293-302.

42. Cummings JL. The Neuropsychiatric Inventory: Assessing psychopathology in dementia patients. Neurology. 1997;48:S10-S16.

This article is protected by copyright. All rights reserved. 
43. Schneeweiss S, Seeger JD, Maclure M, Wang PS, Avorn J, Glynn RJ. Performance of comorbidity scores to control for confounding in epidemiologic studies using claims data. American Journal of Epidemiology. 2001;154:854-864.

44. Connors $\mathrm{MH}$, Ames D, Woodward M, Brodaty $\mathrm{H}$. Mild cognitive impairment and driving cessation: A 3-year longitudinal study. Dement Geriatr Cogn Disord. 2017;44:63-70.

45. Connors $\mathrm{MH}$, Ames $\mathrm{D}$, Woodward M, Brodaty $\mathrm{H}$. Predictors of driving cessation in dementia: Baseline characteristics and trajectories of disease progression. Alzheimer Dis Assoc Disord. 2018;32:57-61.

46. Connors MH, Seeher K, Teixeira-Pinto A, Woodward M, Ames D, Brodaty H. Mild cognitive impairment and caregiver burden: A 3-year-longitudinal study. Am J Geriatr Psychiatry. 2019;27:1206-1215.

47. Epstein-Lubow G, Davis JD, Miller IW, Tremont G. Persisting burden predicts depressive symptoms in dementia caregivers. Journal of Geriatric Psychiatry and Neurology. 2008;21:198-203.

48. Cheng S-T. Dementia caregiver burden: A research update and critical analysis. Curr Psychiatry Rep. 2017;19:64.

49. Pearlin LI, Mullan JT, Semple SJ, Skaff MM. Caregiving and the stress process: An overview of concepts and their measures. The Gerontologist. 1990;30:583-594.

50. Brodaty H, Luscombe G. Psychological morbidity in caregivers is associated with depression in patients with dementia. Alzheimer Dis Assoc Disord. 1998;12:62-70.

51. Taylor BD, Tripodes S. The effects of driving cessation on the elderly with dementia and their caregivers. Accid Anal Prev. 2001;33:519-528.

This article is protected by copyright. All rights reserved. 
52. Torti FMJ, Gwyther LP, Reed SD, Friedman JY, Schulman KA. A multinational review of recent trends and reports in dementia caregiver burden. Alzheimer Dis Assoc Disord. 2004;18:99-109.

53. Covinsky KE, Newcomer R, Fox P, et al. Patient and caregiver characteristics associated with depression in caregivers of patients with dementia. J Gen Intern Med. 2003;18:1006-1014.

54. Miller B, Cafasso L. Gender differences in caregiving: Fact or artifact? The Gerontologist. 1992;32:498-507.

55. Yee JL, Schulz R. Gender differences in psychiatric morbidity among family caregivers: A review and analysis. The Gerontologist. 2000;40:147-164.

56. Langner LA, Furstenberg FF. Gender differences in spousal caregivers' care and housework: Fact or fiction? 2018.

57. Seeher K, Low L-F, Reppermund S, et al. Correlates of psychological distress in study partners of older people with and without mild cognitive impairment $(\mathrm{MCl})$ - the Sydney Memory and Ageing Study. Aging \& Mental Health. 2014;18:694-705.

This article is protected by copyright. All rights reserved. 


\section{Table 1}

Baseline characteristics of patients $(n=720)$

\begin{tabular}{|c|c|}
\hline Characteristic & Baseline Value \\
\hline \multicolumn{2}{|l|}{ Demographics } \\
\hline Age & $78.0(7.5)$ \\
\hline Sex (female) & $338(46.9 \%)$ \\
\hline Education (post-secondary) & $250(34.7 \%)$ \\
\hline Partnered & $553(76.8 \%)$ \\
\hline Living alone & $87(12.1 \%)$ \\
\hline Driving & $225(31.3 \%)$ \\
\hline \multicolumn{2}{|l|}{ Clinical Characteristics } \\
\hline Cognition (MMSE) & $21.5(5.3)$ \\
\hline Function (SMAF) & $-18.1(11.2)$ \\
\hline Neuropsychiatric symptoms (NPI) & $14.5(16.1)$ \\
\hline Number of medications & $6.6(3.6)$ \\
\hline \multicolumn{2}{|l|}{ Dementia Type } \\
\hline Alzheimer's disease & $521(66.9 \%)$ \\
\hline Vascular dementia & $51(6.5 \%)$ \\
\hline Mixed dementia & $129(16.6 \%)$ \\
\hline Lewy body dementia & $16(2.1 \%)$ \\
\hline Frontotemporal dementia & $31(4.0 \%)$ \\
\hline Other & $31(5.0 \%)$ \\
\hline \multicolumn{2}{|l|}{ Caregiver Characteristics } \\
\hline Caregiver burden (ZBI) & $24.0(15.8)$ \\
\hline \multicolumn{2}{|l|}{ Relationship to patient } \\
\hline Spouse & $515(71.5 \%)$ \\
\hline Child & $150(20.8 \%)$ \\
\hline Sibling & $10(1.4 \%)$ \\
\hline Other & $45(6.3 \%)$ \\
\hline Sex (female) & $479(66.5 \%)$ \\
\hline Employed & $152(21.1 \%)$ \\
\hline
\end{tabular}




\section{Level of Services}

No services

$633(87.9 \%)$

Home services

$71(9.9 \%)$

Low level residential care

$16(2.2 \%)$

High level residential care

$0(0.0 \%)$

\section{Table 2}

A linear mixed model analysis examining the relationship between caregiver burden and patient and caregiver characteristics

\begin{tabular}{|c|c|c|c|}
\hline Parameter & Effect Estimate & $95 \% \mathrm{Cl}$ & Sig \\
\hline \multicolumn{4}{|l|}{ Effect of time } \\
\hline Time effect for no services ${ }^{1,2}$ & 0.7 & $0.1,1.3$ & 0.034 \\
\hline Time effect for home services ${ }^{1,3}$ & -0.6 & $-1.8,0.6$ & 0.305 \\
\hline Time effect for low level residential care ${ }^{1,4}$ & 1.5 & $-0.5,3.5$ & 0.148 \\
\hline Time effect for high level residential care ${ }^{1,5}$ & -1.0 & $-4.3,2.3$ & 0.546 \\
\hline \multicolumn{4}{|l|}{ Level of services } \\
\hline No services (at time of diagnosis)* & Ref & & \\
\hline Home services (at time of diagnosis)* & 7.9 & $4.4,11.5$ & $<0.001$ \\
\hline Low level residential care (at time of diagnosis)* & -8.9 & $-14.8,-3.1$ & 0.003 \\
\hline High level residential care (at time of diagnosis)* & -5.8 & $-18.0,6.3$ & 0.346 \\
\hline \multicolumn{4}{|l|}{ Patient Variables } \\
\hline Age at baseline & -0.2 & $-0.3,0.0$ & 0.053 \\
\hline Sex (female) & 1.1 & $-2.4,4.6$ & 0.551 \\
\hline Drivers (vs non-drivers) & -2.5 & $-4.4,-0.6$ & 0.011 \\
\hline Cognition & 0.1 & $0.0,0.3$ & 0.131 \\
\hline Function & -0.2 & $-0.3,-0.1$ & $<0.001$ \\
\hline Dementia severity & 0.1 & $-0.2,0.3$ & 0.623 \\
\hline Neuropsychiatric symptoms & 0.3 & $0.3,0.4$ & $<0.001$ \\
\hline Number of medications & -0.3 & $-0.6,0.0$ & 0.046 \\
\hline \multicolumn{4}{|l|}{ Type of dementia } \\
\hline Vascular dementia^ $^{\wedge}$ & 1.8 & $-3.7,7.2$ & 0.523 \\
\hline Dementia with Lewy Bodies^ & -2.5 & $-11.6,6.5$ & 0.583 \\
\hline Frontotemporal dementia^ & 4.3 & $-3.1,11.7$ & 0.253 \\
\hline
\end{tabular}

This article is protected by copyright. All rights reserved. 
Mixed dementia^

Other dementias^

\section{Caregiver Variables}

Caregiver sex (female)

Caregiver relationship (spouse)

Living status (lives with patient)

Note. For sex of patient and caregiver, estimates of effect are given for females relative to males. For education, estimates of effect are given for those who completed some post-secondary education compared to those who did not. For caregiver relationship, estimates of effect are given for spouses compared to other relationships (other family members, friends). For driving, estimates of effects are given for those driving compared to those not driving. *For level of services, estimates of effects are given compared to no services. ^ For type of dementia, estimates of effects are given compared to patients with Alzheimer's disease. Numbers in bold indicate $p$-values $<0.05$.

${ }^{1}$ The interaction between time and level of services had a p-value of 0.068 and was retained in the model. As such, separate time effects for each service level are reported while the intercept term is not reported. The time effect for no services was significantly greater than the time effect for home services $(p=0.021)$.

${ }^{2}$ Random effect with mean 0.7 and SD $=2.5$.

${ }^{3}$ Random effect with mean -0.6 and $\mathrm{SD}=2.5$.

${ }^{4}$ Random effect with mean 1.5 and $\mathrm{SD}=2.5$.

${ }^{5}$ Random effect with mean -1.0 and $\mathrm{SD}=2.5$. 


\section{Table 3}

A linear mixed model analysis examining the relationship between caregiver burden and individual neuropsychiatric symptoms

\begin{tabular}{|c|c|c|c|}
\hline Parameter & Effect Estimate & $95 \% \mathrm{Cl}$ & Sig \\
\hline \multicolumn{4}{|l|}{ Time } \\
\hline Time effect for no services ${ }^{1,2}$ & 1.2 & $0.7,1.7$ & $<0.001$ \\
\hline Time effect for home services ${ }^{1,3}$ & -0.1 & $-1.0,0.7$ & 0.730 \\
\hline Time effect for low level residential care ${ }^{1,4}$ & 2.9 & $1.7,4.1$ & $<0.001$ \\
\hline Time effect for high level residential care ${ }^{1,5}$ & -0.4 & $-1.9,1.1$ & 0.599 \\
\hline \multicolumn{4}{|l|}{ Level of Services } \\
\hline No services (at time of diagnosis)* & Ref & & \\
\hline Home services (at time of diagnosis) ${ }^{*}$ & 7.1 & $4.5,9.7$ & $<0.001$ \\
\hline Low level residential care (at time of diagnosis) ${ }^{*}$ & -10.6 & $-14.9,-6.2$ & $<0.001$ \\
\hline High level residential care (at time of diagnosis)* & 3.0 & $-3.4,9.4$ & 0.360 \\
\hline \multicolumn{4}{|l|}{ Patient Variables } \\
\hline Age & -0.1 & $-0.2,0.1$ & 0.398 \\
\hline Sex (female) & -1.3 & $-3.1,0.5$ & 0.147 \\
\hline Function & -0.2 & $-0.3,-0.2$ & $<0.001$ \\
\hline Number of medications & -0.4 & $-0.7,-0.2$ & $<0.001$ \\
\hline Antipsychotic medication & -1.6 & $-3.6,0.4$ & 0.123 \\
\hline \multicolumn{4}{|l|}{ Type of Dementia } \\
\hline Vascular dementia^ & 0.4 & $-3.5,4.2$ & 0.850 \\
\hline Dementia with Lewy Bodies^ & -1.5 & $-7.3,4.3$ & 0.605 \\
\hline Frontotemporal dementia^ & 3.7 & $-0.8,8.3$ & 0.104 \\
\hline Mixed dementia^ & 1.6 & $-0.8,4.0$ & 0.192 \\
\hline Other dementias^^ & -3.6 & $-7.9,0.6$ & 0.096 \\
\hline \multicolumn{4}{|l|}{ Neuropsychiatric Symptoms } \\
\hline Delusions & 0.4 & $0.1,0.6$ & 0.003 \\
\hline Hallucinations & 0.6 & $0.3,0.8$ & $<0.001$ \\
\hline Agitation/Aggression & 0.6 & $0.5,0.8$ & $<0.001$ \\
\hline Depression & 0.6 & $0.4,0.8$ & $<0.001$ \\
\hline Anxiety & 0.5 & $0.3,0.6$ & $<0.001$ \\
\hline Euphoria & 0.5 & $0.2,0.7$ & 0.001 \\
\hline Apathy & 0.2 & $0.1,0.4$ & $<0.001$ \\
\hline
\end{tabular}

This article is protected by copyright. All rights reserved. 


$\begin{array}{lccc}\text { Disinhibition } & 0.1 & -0.1,0.4 & 0.154 \\ \text { Irritability } & 0.5 & 0.4,0.7 & <0.001 \\ \text { Aberrant Motor } & 0.3 & 0.2,0.5 & <0.001 \\ \text { Night-Time Behaviour } & 0.0 & -0.2,0.1 & 0.708 \\ \text { Appetite } & 0.2 & 0.1,0.4 & \mathbf{0 . 0 0 2}\end{array}$

Note. For sex, estimates of effect are given for females relative to males. *For level of services, estimates of effects are given compared to no services. ^For type of dementia, estimates of effects are given compared to patients with Alzheimer's disease. Numbers in bold indicate p-values $<0.05$. ${ }^{1}$ The interaction between time and level of services had a $p$-value of $<0.001$ and was retained in the model. As such, separate time effects for each service level are reported while the intercept term is not reported. The time effect for no services was significantly greater than the time effects for home services $(p=0.001)$ and high level residential care $(p=0.034)$ and significantly lower than the time effect for low level residential care $(p=0.006)$.

${ }^{2}$ Random effect with mean 1.2 and $\mathrm{SD}=2.7$.

${ }^{3}$ Random effect with mean -0.1 and $\mathrm{SD}=2.7$.

${ }^{4}$ Random effect with mean 2.9 and SD $=2.7$.

${ }^{5}$ Random effect with mean -0.4 and $\mathrm{SD}=2.7$. 


\title{
Figure 1 (title and legend)
}

Number of patient-caregiver dyads with completed Zarit Burden Interview data at each time point

[Figure uploaded separately]

\begin{abstract}
a68 participants completed the 6 month follow-up but not 3 month follow-up b31 participants completed the 12 month follow-up but not 6 month follow-up c9 participants completed 2 year follow-up but not the 1 year follow-up d8 participants completed 3 year follow-up but not the 2 year follow-up
\end{abstract}




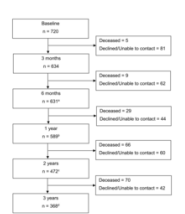

GPS_5244_PRIME_DementiaCaregiverBurden Figure 1_191116.tiff

This article is protected by copyright. All rights reserved. 


\section{University Library}

\section{- M M I E E R VA A gateway to Melbourne's research publications}

Minerva Access is the Institutional Repository of The University of Melbourne

Author/s:

Connors, MH;Seeher, K;Teixeira-Pinto, A;Woodward, M;Ames, D;Brodaty, H

Title:

Dementia and caregiver burden: A three-year longitudinal study

Date:

2019-12-10

Citation:

Connors, M. H., Seeher, K., Teixeira-Pinto, A., Woodward, M., Ames, D. \& Brodaty, H.

(2019). Dementia and caregiver burden: A three-year longitudinal study. INTERNATIONAL JOURNAL OF GERIATRIC PSYCHIATRY, 35 (2), pp.250-258. https://doi.org/10.1002/ gps.5244.

Persistent Link:

http://hdl.handle.net/11343/286726 